\title{
THE
}

$5-21-2020$

\section{The Neutrally Buoyant Sediment Trap: Two Decades of Progress}

\author{
Margaret Estapa \\ James Valdes \\ Kaitlyn Tradd \\ Jackson Sugar \\ Melissa M. Omand \\ University of Rhode Island, momand@uri.edu
}

See next page for additional authors

Follow this and additional works at: https://digitalcommons.uri.edu/gsofacpubs

Creative Commons License

cc) (i)

This work is licensed under a Creative Commons Attribution 4.0 License.

\section{Citation/Publisher Attribution}

Estapa, M., J. Valdes, K. Tradd, J. Sugar, M. Omand, and K. Buesseler, 2020: The Neutrally Buoyant Sediment Trap: Two Decades of Progress. J. Atmos. Oceanic Technol., 37, 957-973, https://doi.org/ 10.1175/JTECH-D-19-0118.1.

This Article is brought to you for free and open access by the Graduate School of Oceanography at DigitalCommons@URI. It has been accepted for inclusion in Graduate School of Oceanography Faculty Publications by an authorized administrator of DigitalCommons@URI. For more information, please contact digitalcommons-group@uri.edu. 
Authors

Margaret Estapa, James Valdes, Kaitlyn Tradd, Jackson Sugar, Melissa M. Omand, and Ken Buesseler

This article is available at DigitalCommons@URI: https://digitalcommons.uri.edu/gsofacpubs/729 


\title{
${ }^{\curvearrowright}$ The Neutrally Buoyant Sediment Trap: Two Decades of Progress $\mathscr{\bullet}$
}

\author{
MARGARET ESTAPA \\ Skidmore College, Saratoga Springs, New York \\ JAMES VALDES AND KAITLYN TRADD \\ Woods Hole Oceanographic Institution, Woods Hole, Massachusetts \\ JACKSON SUGAR AND MELISSA OMAND \\ University of Rhode Island, Narragansett, Rhode Island \\ KEN BUESSELER \\ Woods Hole Oceanographic Institution, Woods Hole, Massachusetts
}

(Manuscript received 17 July 2019, in final form 22 January 2020)

\begin{abstract}
The biological carbon flux from the ocean's surface into its interior has traditionally been sampled by sediment traps, which physically intercept sinking particulate matter. However, the manner in which a sediment trap interacts with the flow field around it can introduce hydrodynamic biases, motivating the development of neutral, self-ballasting trap designs. Here, the performance of one of these designs, the neutrally buoyant sediment trap (NBST), is described and evaluated. The NBST has been successfully used in a number of scientific studies since a prototype was last described in the literature two decades ago, with extensive modifications in subsequent years. Originated at Woods Hole Oceanographic Institution, the NBST is built around a profiling float and carries cylindrical collection tubes, a feature that distinguishes it from other neutral traps described in the literature. This paper documents changes to the device that have been implemented over the last two decades, including wider trap tubes; Iridium Communications, Inc., satellite communications; and the addition of polyacrylamide gel collectors and optical sedimentation sensors. Information is also provided with the intent of aiding the development of similar devices by other researchers, including the present adaptation of the concept to utilize commercially available profiling float hardware. The performance of NBSTs built around commercial profiling floats is comparable to NBSTs built around customized floats, albeit with some additional operational considerations. Data from recent field studies comparing NBSTs and traditional, surface-tethered sediment traps are used to illustrate the performance of the instrument design. Potential improvements to the design that remain to be incorporated through future work are also outlined.
\end{abstract}

D Denotes content that is immediately available upon publication as open access.

Supplemental information related to this paper is available at the Journals Online website: https://doi.org/10.1175/JTECH-D-190118.s1.

Corresponding author: Margaret Estapa, mestapa@skidmore.edu

\section{Introduction}

\section{a. Scientific motivation}

Much of the biological carbon flux from the sunlit, euphotic zone of the ocean into the meso- and bathypelagic zones is carried by sinking particles. These particles also compose an important source of energy for deep food webs. Observational studies investigating the biological origins, physical properties, and chemical composition of this sinking material have traditionally utilized sediment traps to collect samples of the settling material. Sediment traps are devices that separate sinking 
particles in the ocean from the much more numerically abundant nonsinking particles, by physically intercepting them during their downward transit. The downward sinking flux is quantified as the particles collected at a given depth over a set time period in a trap sample tube or funnel of fixed collection area. However, horizontal ocean currents are typically orders of magnitude larger than particle sinking velocities (Siegel and Deuser 1997). Therefore, the manner in which a sediment trap interacts with the flow field around it will influence how accurately it separates sinking from nonsinking particles. Important is that most sediment traps used in studies reported in the literature are "surface tethered" to drifting surface buoys or moored to the bottom, which leads to potentially strong interactions with the flow field, particularly in the upper mesopelagic (the upper $\sim 1 \mathrm{~km}$ of the ocean).

A variety of different, surface-tethered trap designs for use in the upper mesopelagic have been employed over the past few decades, each with its own set of advantages and disadvantages. These design considerations have been reviewed elsewhere in detail (Buesseler et al. 2007b; McDonnell et al. 2015). The primary objective is to quantitatively collect the passively sinking particle flux while avoiding any collection of suspended particles or material transported vertically by zooplankton "swimmers." A high trap aspect ratio prevents eddies in the mouth of the trap from penetrating into the bottom and disturbing the accumulated sample. Because the sinking particle flux is spatiotemporally variable in many systems, a secondary objective is to collect large enough samples to average over this variability; however, this involves trade-offs with the trap's aspect ratio. Other trap features are meant to limit the creation of these eddies in the first place by minimizing fluid flow across the trap mouth. Such design features include "wind vanes" to point traps into the ambient flow, gimballed collection tubes, and inclusion of a bungee in the upper part of the trap mooring to dampen surface motions. Swimmer exclusion is also difficult, and techniques range from mechanical exclusion devices such as the indented rotating sphere (Lee et al. 2009) and the "labyrinth of doom" (Coale 1990), to manual removal by the researchers after the sample has been collected.

The variety of sediment trap designs currently in use, and the complex, interacting factors that influence trap performance, make comparisons between different designs difficult to interpret. However, fluid flow around the trap lies at the heart of most of the causes of trap inaccuracies that have been put forward. A priori, elimination of flow around a sediment trap will improve its collection characteristics. Here we document two decades of improvements made to a family of neutrally buoyant sediment traps (NBSTs) that have been specifically designed to minimize effects associated with fluid flow across a cylindrical trap opening by avoiding tethering the trap to a surface-drifting buoy. Unlike surface-tethered traps (STTs), NBSTs are selfballasting, drifting at their sampling depths without any surface expression. The Woods Hole Oceanographic Institution (WHOI)-designed prototype of the NBST was described by Valdes and Price (2000) and has since undergone continuous improvements, while simultaneously being employed in a series of successful field studies but without a corresponding, updated technical description. In recent years, studies of sinking particulate matter in the ocean have come to rely on increasingly sophisticated sensors, and platforms with ever greater autonomy have been proposed. The NBST will need to continue to evolve to meet these needs in the future. The motivation of this paper is to provide to the community the information necessary to employ and expand the capabilities of future NBSTs, as well as to provide a reference for researchers interested in the details of NBSTs used in prior studies.

\section{b. Prior studies utilizing NBSTs and comparisons with other trap types}

The key studies in which NBSTs have been used and updated over the last two decades are given in Table 1. Prototype NBSTs were first tested at the Bermuda Atlantic Time Series Study (BATS) site in 1997 and 1998. In these initial tests, the untethered traps collected different amounts and compositions of particles compared to codeployed surface-tethered, VERTEX-style particle interceptor traps (PITs; Buesseler et al. 2000; Stanley et al. 2004). After making a number of technical improvements (described below), updated NBSTs were employed in the Vertical Transport In the Global Ocean (VERTIGO) program with field studies conducted in 2004 and 2005 at Station Aloha and K2 in the North Pacific Ocean (Buesseler et al. 2007a). Again, the NBSTs were deployed alongside arrays of surface-tethered sediment traps and were found to collect with higher efficiency under high flux conditions, although the causes for differences were ambiguous (Lamborg et al. 2008). A 3-yr intercomparison between NBSTs and the standard surface-tethered PITs employed in the BATS program was carried out between 2007 and 2010 to better understand differences between the trap designs under varying conditions of flow and particle flux (Owens et al. 2013). In this study, fluxes to the two trap types generally agreed within a factor of 2 , but they differed during periods of very low flux (when PITs 


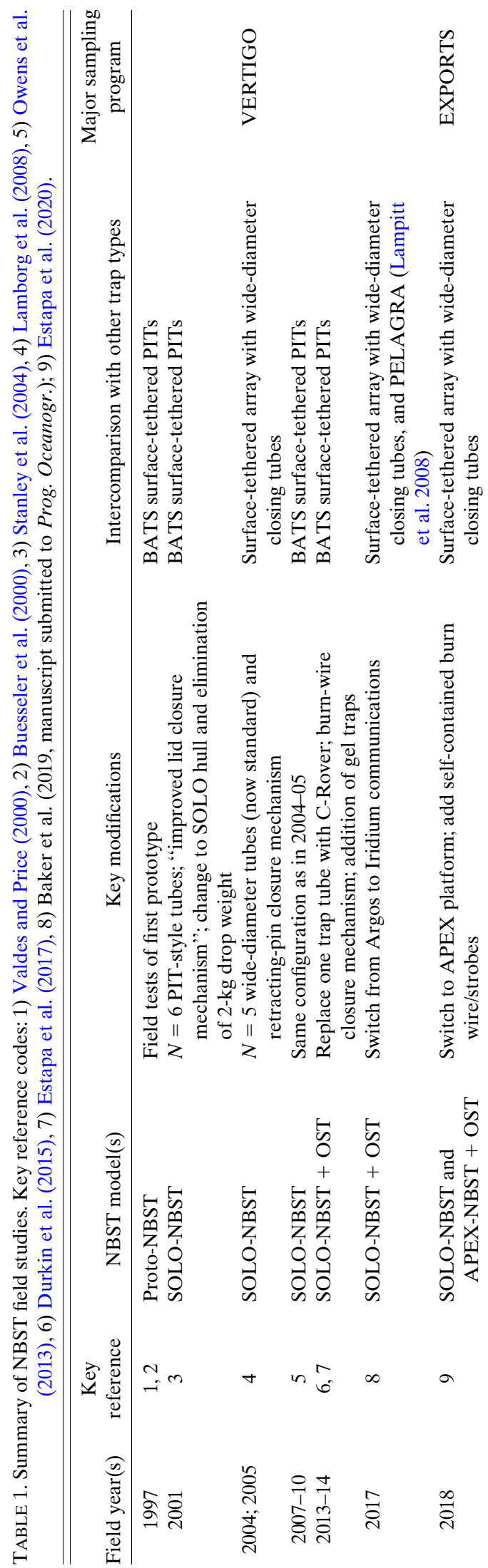

undercollected relative to NBSTs) and when the PITs were within the surface mixed layer. As part of a program calibrating transmissometers on profiling floats for use as "optical sediment traps" (OSTs; Estapa et al. 2017), NBSTs were again deployed alongside the standard BATS PITs during 5 months in 2013 and 2014. They were modified to carry vertically mounted transmissometers (WETLabs C-Rover 2000) and polyacrylamide gel collectors in some trap tubes (Durkin et al. 2015).

To our knowledge, three other neutral, self-ballasting sediment trap designs have been implemented by other research groups. The Particle Export Lagrangian (PELAGRA) trap was designed at the National Oceanography Centre (NOC), Southampton, United Kingdom (Lampitt et al. 2008), and consists of an arrangement of four conical traps with $0.5-\mathrm{m}^{2}$ openings around an APEX float (Teledyne Webb Research, Inc.), with mechanically opening and closing collection jars. Another neutral trap, the Lagrangian sediment trap (LST; Sherman et al. 2011) was designed at the Monterey Bay Aquarium Research Institute (MBARI) with the specific goal of sampling sinking particulates at depth below drifting icebergs. It also contained four mechanically opening and closing conical traps (each with a $0.08-\mathrm{m}^{2}$ opening) arranged around a Sounding Oceanographic Lagrangian Observer (SOLO; Davis et al. 2001) float. A similar system was designed to calibrate the optical sensors carried aboard the Carbon Flux Explorer (CFE-Cal; Bourne et al. 2019). The CFE-Cal device consisted of a high-aspect-ratio, conical funnel leading to a rotating carousel of sample collection bottles, all carried aboard a SOLO float. A comparison deployment between the WHOI-designed NBST and the NOC-designed PELAGRA (Baker et al. 2019, manuscript submitted to Prog. Oceanogr.) suggested good correspondence between the bulk compositions of particles collected by each trap type, but lower total fluxes to the PELAGRA traps (see section 3a, below). No other intercomparisons have been attempted among the different neutral trap designs. However, several comparison studies of NBSTs and different STT designs have been carried out. The results of these studies are summarized in Table 2.

Of the four designs currently described in the literature, only the NBST and PELAGRA can accommodate gel collectors, which have recently become important tools for quantifying sinking particle size distributions, morphologies, and biological identities (Ebersbach and Trull 2008; McDonnell and Buesseler 2010, 2012; Durkin et al. 2015; Flintrop et al. 2018). Only the NBST carries cylindrical collection tubes, whose vertical walls minimize hydrodynamic effects as well as the risks of particle 


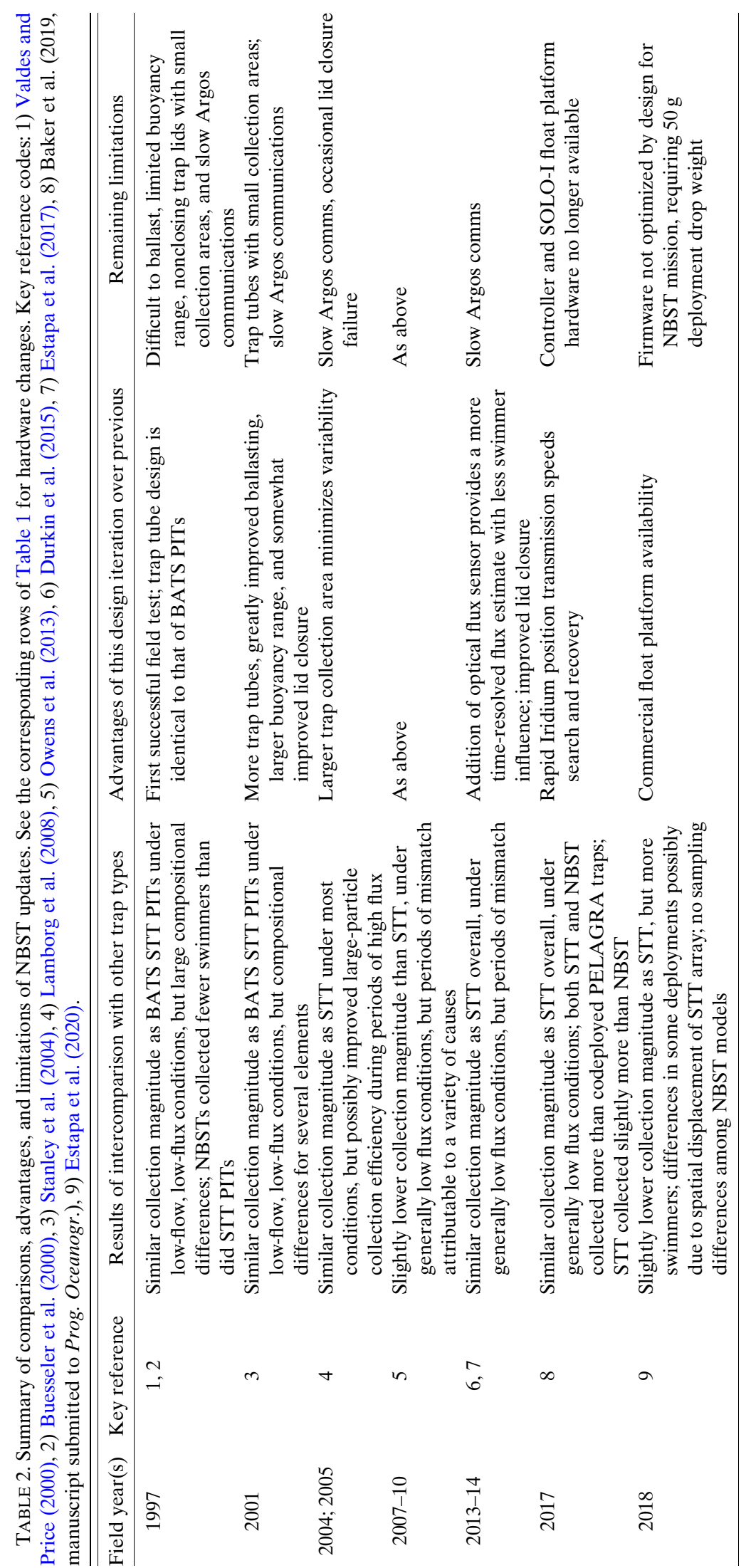


aggregation, adhesion, and concentration around collection jar edges (problematic for gel traps) that are inherent in conical trap designs. To date, none of these four trap designs can easily be constructed or deployed except by their originating institutions, in spite of the fact that the PELAGRA and NBST are now being deployed as part of large, multiinstitutional studies of the biological pump (e.g., Siegel et al. 2016; Sanders et al. 2016). With this manuscript, our goal is to provide an updated technical description of the WHOI-designed NBST, covering all changes since Valdes and Price (2000) last described a prototype of the instrument. We include the latest shift of the NBST design to the commercially available APEX float platform, which we hope may allow other laboratories to implement their own NBSTs of similar design.

\section{c. Original prototype NBST as described by Valdes and Price (2000)}

The original NBST described by Valdes and Price (2000), a prototype of the current version, is summarized here. The prototype NBST (protoNBST) consisted of a cylindrical hull $11 \mathrm{~cm}$ in diameter by $128 \mathrm{~cm}$ long, which supported four VERTEX-style cylindrical sediment trap tubes $(7.5 \mathrm{~cm}$ in diameter by $66 \mathrm{~cm}$ long; Knauer et al. 1979) with lids attached via elastic cords. Like most profiling floats, active buoyancy control was achieved by pumping oil into and out of the rigid aluminum hull into a flexible, external bladder, thereby changing the float's volume while maintaining constant mass. Unlike the later floats used for the NBST (further described below), the protoNBST had a $12-\mathrm{cm}^{3}$ volume range, sufficient only to fine tune its density near the target depth, and required extraordinarily careful ballasting prior to deployment. A burn wire, activated at the end of a 2-5-day deployment, released a 2-kg drop weight and allowed the trap tube lids to close. The buoyancy engine, burn wire, pressure sensor, and Argos communications were controlled by a Tattletale 4 datalogger (Onset Computer, Inc.). The protoNBST had a mass in air of approximately $16 \mathrm{~kg}$ and carried battery packs sufficient for five missions of approximately 5 days in length.

\section{Current NBST models}

\section{a. SOLO-based NBST}

\section{1) Design updates}

The first successful deployments of the protoNBST in 1997 were accompanied by a number of "lessons learned" (Valdes and Price 2000) that led to immediate changes to the NBST's design, prior to its use in larger field programs. The hull was changed from the original prototype version to the SOLO hull and buoyancy engine (Davis et al. 2001), which had a volume range of about $200 \mathrm{~cm}^{3}$ and a pneumatic air system with a sleeve bladder, and which provided additional buoyancy at the surface (Fig. 1). These changes permitted the elimination of the 2-kg drop weight, which had been required by the protoNBST for it to resurface. However, even with the larger buoyancy capacity, the elimination of the drop weight required careful ballasting for the expected in situ density profile prior to deployment in each new field setting. The SOLO-NBST utilized a customized top cap assembly for the float, which has evolved over time to permit addition of sensors and changes in communications hardware (below).

Another early change was the replacement of the four 7.5-cm-diameter VERTEX-style trap tubes with five 12.7-cm-diameter, 70-cm-long tubes (Lamborg et al. 2008; Fig. S1 in the online supplemental material). The new tube design, still in use at present with small modifications, addressed the need for larger sample collection areas to better constrain the large variability in particle flux at small scales (Buesseler et al. 2000). The tube bodies are constructed of polycarbonate, with ultrahigh-molecular-weight polyethylene (UHMW-PE) lids and bottoms made of UHMW-PE or, more recently, high-density polyethylene (HDPE) (see below). The bottoms terminate in a polyvinyl chloride (PVC) ball valve to permit sample collection without disassembly of the tube. Lids are attached with silicone rubber elastic cord running down the center of the tube and anchored to a polycarbonate anchor bar extending across the tube interior (Fig. 2; supplemental Fig. S1). In SOLO-NBSTs from the mid-2000s, a retracting-pin mechanism held the trap lids open via monofilament lanyards at the start of a deployment and released the lanyards so that the tension in the elastic cord would pull the lids closed prior to the SOLO-NBST resurfacing. The retracting pin was prone to fouling and was replaced with a burn-wire release in 2010. In this present configuration, the lanyards from the tube lids are attached to the corroding burn-wire loop using cable ties. Tubes also have polycarbonate baffles near their mouths to minimize turbulent eddies entering the traps and to exclude large swimmers. Baffles are $1 \mathrm{in}$. $(2.54 \mathrm{~cm})$ thick and have openings $3 / 8$ in. $(0.953 \mathrm{~cm})$ in diameter (Lamborg et al. 2008). Three PVC snap rings secure the elastic cord's anchor bar and baffles in place inside the tubes. Tube bottoms were originally attached to the tube bodies with a face seal and four screws that threaded directly into the polycarbonate (Fig. 1). Over time the UHMW-PE tended to deform around the attachment points, so the most recent design employs a radial seal between the tube bottom and body, along with a monofilament Ortman key-and-groove connection. Tube bottoms 


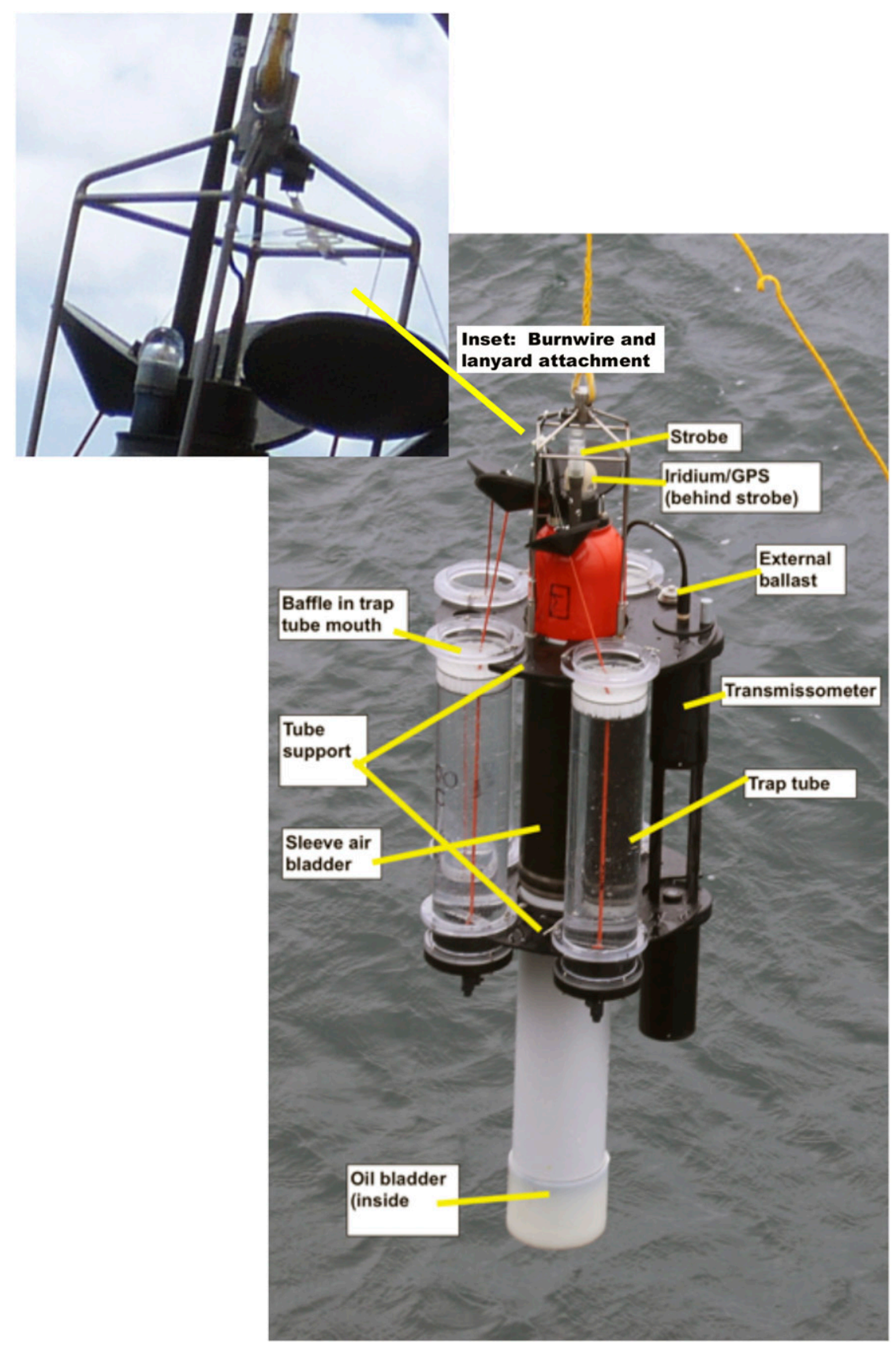

FIG. 1. Annotated photograph of SOLO-NBST configured for deployment in April 2017 (photograph from C. Baker of the National Oceanography Centre, Southampton, United Kingdom). Not visible in the photograph are clamps around the float's hull, beneath the tube support plates. Inset: Detail showing burn-wire loop and attachment of trap-lid lanyards via cable ties (photograph from C. Durkin of Moss Landing Marine Laboratories, Moss Landing, California).

are also now cut from HDPE, which has a lesser tendency to creep after machining (supplemental Fig. S1).

Tubes (and, more recently, external sensors) are secured to the NBST by locking into a set of upper and lower tube support plates (Fig. 1). The plates rest on top of two $3.81-\mathrm{cm}$-thick (1.5 in.) clamps that bolt around the SOLO hull immediately above and below the sleeve bladder. Both plates and clamps are cut from sheets of UHMW-PE. Also bolted into the upper clamp, over the hull's top cap, is a lifting cage made of welded titanium. A 7-8-m-long, $0.953-\mathrm{cm}(0.375 \mathrm{in}$.) polypropylene line is permanently spliced into the 


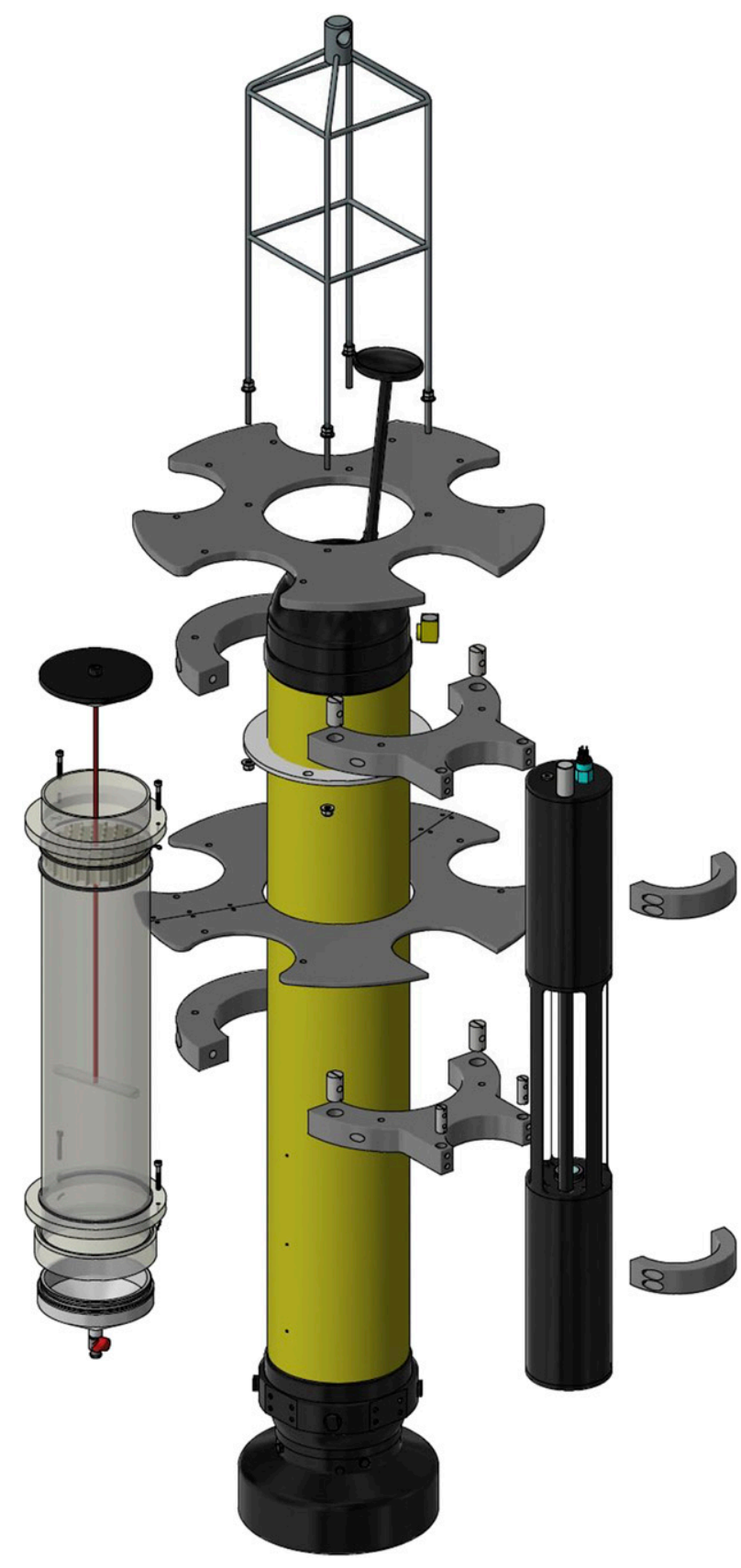

FIG. 2. Schematic illustrating assembly of trap parts around the profiling float hull (in this case, an APEX float).

top of the lifting cage and protected from chafing by a sleeve cut from $1.27-\mathrm{cm}$-inner-diameter ( $0.5 \mathrm{in}$.) Tygon tubing. A fully assembled SOLO-NBST, including all tubes and trap support hardware, but not sampling fluids or seawater in the trap tubes, has a mass of approximately $29 \mathrm{~kg}$ in air and weighs $1.7 \mathrm{~kg}$ in water.

Beginning in 2013, transmissometers (C-Rover 2000; $25-\mathrm{cm}$ pathlength and $650 \mathrm{~nm}$; WETLabs, Inc.) were added to the SOLO-NBSTs to operate as optical sediment traps (Bishop et al. 2004; Bishop and Wood 2009; Estapa et al. 2013, 2017, 2019a). This allows optical attenuance fluxes to be calibrated with respect to the chemical fluxes collected in the trap tubes and provides a more time-resolved proxy for particle flux than can be obtained from the bulk samples in the tubes (Estapa et al. 2017). The controller samples the C-Rover at a user-selected sampling interval (either every 15 or $30 \mathrm{~min}$ ) and records the digital values from the sensor over an RS-232 interface. The C-Rover 2000 transmissometer housing is designed for use with profiling floats and other similar platforms, and adds a net weight in water of approximately $100 \mathrm{~g}$ to the total.

\section{2) BALLASTING AND OPERATION}

Ballasting of a newly constructed NBST is conducted in three steps. First, the water volume displaced by the float and the precut, 2-3 m-long polypropylene retrieval line (without external trap parts or sample solutions) as a function of pressure is measured over a range from 100 to $500 \mathrm{dbar}$, where $500 \mathrm{dbar}$ is the maximum deployment pressure of the instrument. The displacement measurements are performed with the float's piston set approximately $50 \mathrm{~cm}^{3}$ short of full retraction (the "ballast position"). Second, the weight in water of all external trap parts, sensors, and sample solutions is determined to a precision of $\pm 2 \mathrm{~g}$ in a 10-m-deep tank full of water with known temperature and density, using a hanging load-cell balance. The external parts are prone to retaining air bubbles, and the materials from which they are constructed have high coefficients of thermal contraction, so long equilibration times and careful attention to releasing entrapped air are necessary. The displacement of these external parts, and their expected weight in water at the deployment temperature and density, are computed from the tank measurements. This includes a correction for the compressibility and thermal contraction of parts made of polycarbonate, UHMW-PE, and HDPE (Middaugh and Goudey 1993), whose separate displacements are also measured in the tank. Last, dry mass (contained in bottles of lead shot) is added or removed from inside the hull to compensate for the predicted in situ weight of the external parts. An additional 100$150 \mathrm{~g}$ of stainless steel washers are bolted onto and ballasted with the external parts to allow additional small adjustments to be made in the field, without opening the hull (Fig. 1).

The custom-designed controller based on the Onset Tattletale datalogger has continued to evolve, but the buoyancy control algorithm has remained fairly consistent over time. The core mission steps are summarized 
here. Prior to launch, the SOLO-NBST is programmed using terminal software on a computer connected via an RS-232 interface. The clock is manually resynchronized with time aboard the ship, and the desired date and time of resurfacing are set. The user also enters the target pressure and the desired data-logging interval at depth (either every 15 or $30 \mathrm{~min}$ ). The SOLO-NBST will adjust its buoyancy until it achieves a pressure within a certain margin around the target, referred to as the "deadband." The user selects this to be either 10 or 25 dbar. The user initiates the mission via the serial interface and then disconnects, with final activation just prior to launch accomplished on deck using a magnetic switch.

Final activation initiates a mission sequence that continues until the resurfacing time is reached, or if any of several failure conditions (pressure, battery, or internal vacuum) are met. This sequence is illustrated in a flowchart (Fig. S2 in the online supplemental material). Initially, the controller retracts the piston to the ballast position, and begins checking the pressure once per minute until the NBST has reached a pressure of 30 dbar at which point it begins active buoyancy control. If $80 \mathrm{~min}$ elapse and the SOLO-NBST is still trapped near the surface, then active buoyancy control cycle will begin regardless, to allow the controller to sleep and conserve power. For the first $4 \mathrm{~h}$, a pressure check is executed every $15 \mathrm{~min}$ and ballast adjustments made every $30 \mathrm{~min}$; after $4 \mathrm{~h}$ autoballasting occurs once every 30 min (Fig. S3 in the online supplemental material). In between pressure checks, the controller sleeps to conserve power. During autoballasting, the controller checks whether the SOLO-NBST is outside the target pressure deadband, calculates the offset between its actual and its target pressure, and if necessary, performs a buoyancy correction that is proportional to the offset. This autoballasting algorithm allows the SOLO-NBST to settle at its target depth within a few hours of deployment, without requiring routine user adjustments at sea, even when there are ballasting errors of tens of grams (Fig. 3), which was a primary goal identified early in prototype development (Valdes and Price 2000).

When the mission reaches its programmed end time, the controller activates a burn wire to release the trap tube lids, which are pulled shut by their elastic cords. The piston is then fully extended and the air bladder is inflated when the SOLO-NBST reaches the surface to provide additional height in the water. After the SOLO-NBST surfaces, a GPS position is acquired and transmitted at intervals to aid recovery, and at night (determined by controller clock time) a flashing strobe is activated. Argos communications were originally

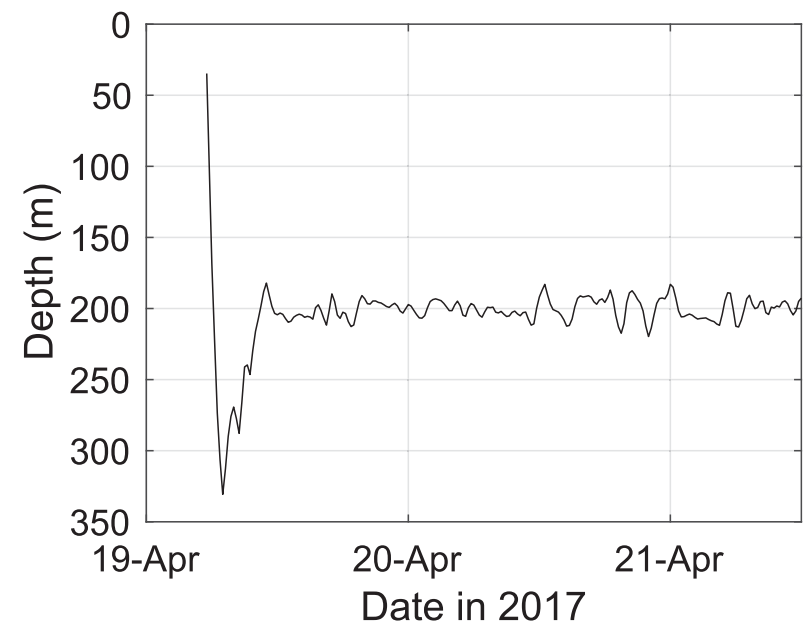

FIG. 3. Example of pressure-vs-time data from a deployment in which the SOLO-NBST was too heavy for its target depth of $200 \mathrm{~m}$.

used, with the GPS position and battery/vacuum status encoded into the messages transmitted for recovery. In 2013, GPS/Argos was replaced by a self-contained, off-the-shelf GPS/Iridium (satellite) beacon (iCBN from MetOcean Telematics), which the controller simply power cycles at intervals while the NBST is awaiting recovery. Recovery of the SOLO-NBST typically involves careful vessel maneuvers to approach within $5-10 \mathrm{~m}$ of the device, at which point the floating polypropylene retrieval line is picked up with a pole or a grapple and attached to a crane or winch to lift the trap out of the water.

The current SOLO-NBST runs on three custom alkaline battery packs, two of which drive the oil and air systems, and the third of which powers the controller. Together the two pump batteries provide a capacity of $22 \mathrm{~A} \mathrm{~h}$ at a nominal $13.5 \mathrm{~V}$. While the SOLO-NBST is on a mission, the current draw on the pump batteries is less than $10 \mu \mathrm{A}$ when inactive, less than $100 \mathrm{~mA}$ when retracting, and $400-600 \mathrm{~mA}$ when extending. The controller battery provides a capacity of $15 \mathrm{Ah}$ at a nominal $10.5 \mathrm{~V}$, supplies approximately 36-50 $\mathrm{mA}$ during active depth control or data acquisition, and provides less than $150 \mu \mathrm{A}$ while asleep. The controller battery pack requires replacement more frequently than the pump batteries, and typically is changed after about five missions or when the voltage drops to $9 \mathrm{~V}$.

\section{b. APEX-based NBST}

The discontinuation of the commercial Tattletale line of dataloggers and the limited availability of new SOLO-I floats required adaptation of the NBST design 


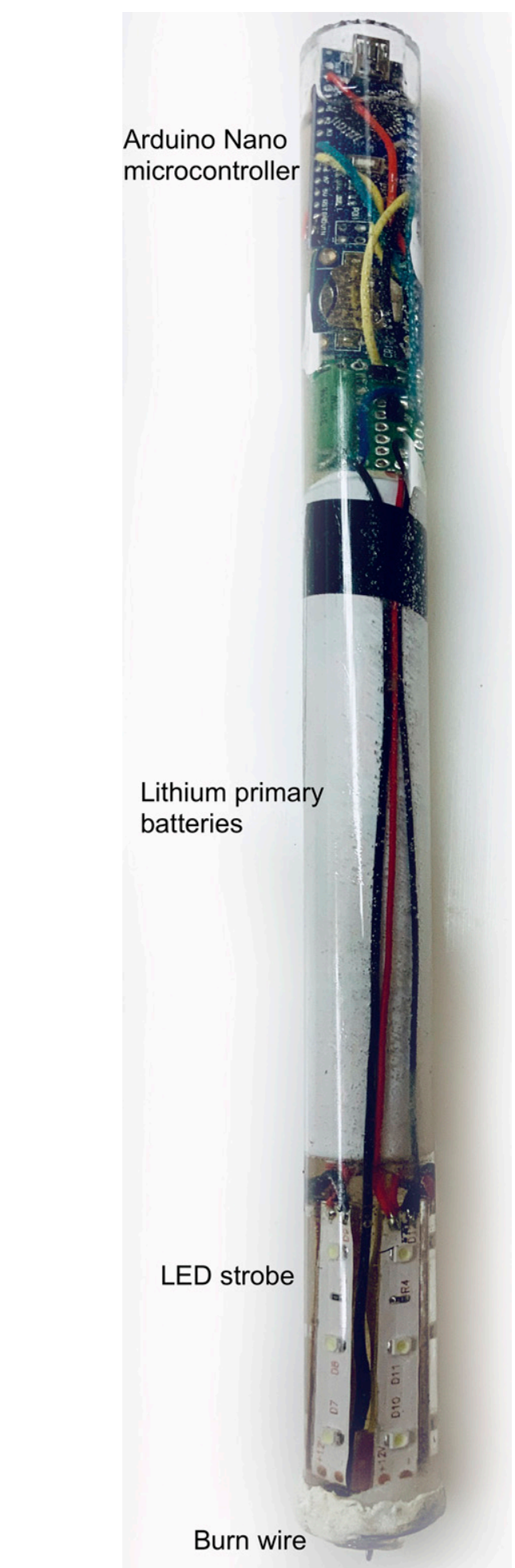

FIG. 4. Photograph of standalone burn-wire/strobe unit employed with APEX-NBSTs. Major components are annotated; see the text for details. The unit housing is approximately $25 \mathrm{~cm}$ long. to work with a new controller and float. To allow broader use of the design by more research groups, we decided to utilize a commercial platform. Encouraged by the success of the PELAGRA traps' integration with APEX floats (Teledyne Webb Research), we constructed several new "APEX-NBSTs" around the same platform in 2018. These have a broadly similar design to the SOLO-NBST, with some key modifications to the tube bottom attachments and retrieval aids. Although we have not attempted this, the APEX float platform is likely to allow NBST deployments to deeper depths and higher pressures (up to 2000 dbar) with careful ballasting. A detailed diagram and materials list for the APEX-NBST are included in Fig. S1 of the online supplemental material. In addition, the ballasting strategy and mission programming requirements differ. These changes are described below.

A stand-alone, programmable, expendable unit was designed to fulfill the need for a standalone recovery strobe, and a release mechanism for the trap lids on the APEX-NBSTs (Fig. 4). These burn wire/strobes are controlled by an Arduino Nano microcontroller. Arduino was selected because the platform has plenty of documentation and is trivial to program from any computer with no extra equipment. Accurate timing is achieved via a real-time clock to ensure that that the recovery aid functionality would not be affected were the Arduino to briefly lose power. The electronics, battery, and strobe are potted within an acrylic tube (25.4-cm length; $2.54-\mathrm{cm}$ outer diameter) sealed at both ends with "WaterWeld" epoxy putty. The strobe consists of 16 high-intensity white light-emitting diodes (LEDs) arranged annularly within the tube. Power (12 V) is supplied by four CR123A lithium primary batteries connected in series. The burn-wire portion consists of a loop of Inconel 625 wire acting as the anode, surrounded by a brass washer as the cathode, and separated by a plastic bushing. Both the LEDs and burn wire are actuated by two overrated N-channel metal oxide semiconductor field-effect transistors (MOSFETs). The burn wire receives $5.3 \mathrm{~W}$ of power and takes roughly $20 \mathrm{~min}$ to dissolve. Over 50 of the burn wires have been tested in the field at depths typically ranging from 100 to $500 \mathrm{~m}$. In one test, a unit performed successfully at $900 \mathrm{~m}$. During the 2018 Export Processes in the Ocean from Remote Sensing (EXPORTS) deployments described below (section 3b), failure of the units at a rate of roughly one in five was observed initially and was traced to ineffective application of WaterWeld putty after programming. Once this issue was resolved, the failure rate dropped to zero.

In developing the APEX-based NBST, we aimed to replicate the behavior of the original custom SOLONBST controller as closely as possible using the APF-11 


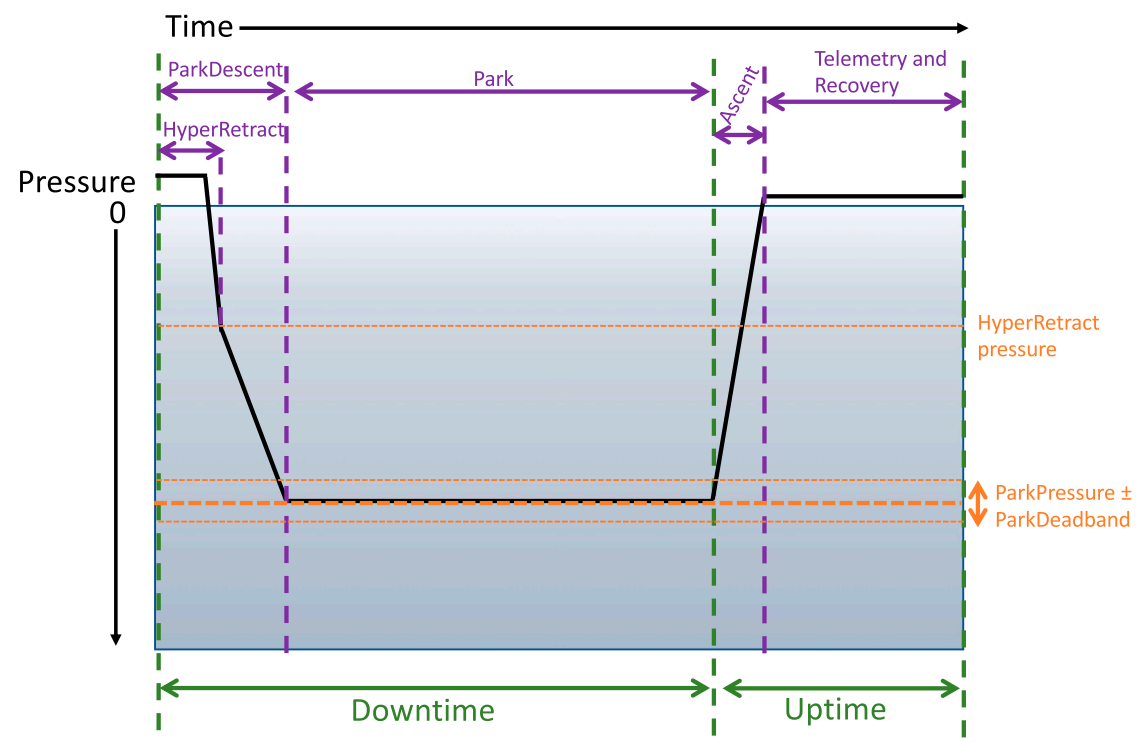

FIG. 5. Schematic illustrating phases of the APEX mission cycle (purple) and key, configurable pressure and time intervals that together are used to define the APEX-NBST mission (orange and green). The solid black line shows the depth-vs-time path of the float, beginning with predeployment and ending with recovery. Purple time intervals are labeled with the phases of a typical mission cycle. The DownTime and UpTime time periods are labeled in green. Orange lines show HyperRetract and Park depths and the Park deadband margin.

float controller (Teledyne Webb Research) and APEX firmware. The APEX float's standard mission cycle and adjustable parameters are similar to many commercially available profiling floats developed for use in the Argo program. Here, we retain common terms describing the parts of this cycle. For readers unfamiliar with the Argo float cycle, we briefly describe the steps below and illustrate key time and depth intervals in Fig. 5, while the flowchart in Fig. 6 illustrates the mission sequence.

Ensuring rapid descent of the APEX-NBST from the surface upon deployment required an additional hyperretract modification to the firmware, and the inclusion of a timed, 20-min, 50-g drop weight to compensate for entrapped air (the details are described later). The modified APEX mission (Figs. 5 and 6, with configuration details reproduced in the online supplemental material) begins with manual activation by the operator and skips the predescent system testing, which must be performed manually. The float immediately begins the "ParkDescent" mission phase and at the same time, enters "HyperRetract" mode, which retracts the piston fully until the float descends past a preset pressure ("HyperRetractPressure") or until the ParkDescent phase ends. ParkDescent continues until one of two conditions is reached: either the platform reaches the top of its target pressure window or the ParkDescent phase times out. When either condition is satisfied, the platform enters the "Park" mission phase. If the float has not yet reached the target pressure window, it adjusts its buoyancy to the preprogrammed target. From this point until the expiration of the Park phase, the float checks its pressure on a fixed time interval and, if outside the target pressure window for three consecutive periods, performs a single buoyancy adjustment of preset magnitude.

When the Park mission phase expires ("DownTime"), the "UpTime" portion of the mission cycle begins (Figs. 5 and 6). In parallel, the independently timed burn-wire controller closes the sediment trap lids. While APEX floats used in a typical Argo-like mission (http://www.argo.ucsd.edu) would execute a deep descent prior to ascending to the surface, we disable this behavior so that the minimum amount of time elapses between closure of the trap lids and the float's ascent to the surface. Conservatively, we budget an extra hour for the burn wire to release the trap lids, and then the float begins its ascent. When the float reaches the surface, it begins its telemetry cycle. Prior to the float's initiation of telemetry, a new mission that activates "Recovery Mode" must be queued for transmission. In Recovery Mode, the float inflates its air bladder and activates a built-in strobe, while transmitting its GPS location and a short status message. 


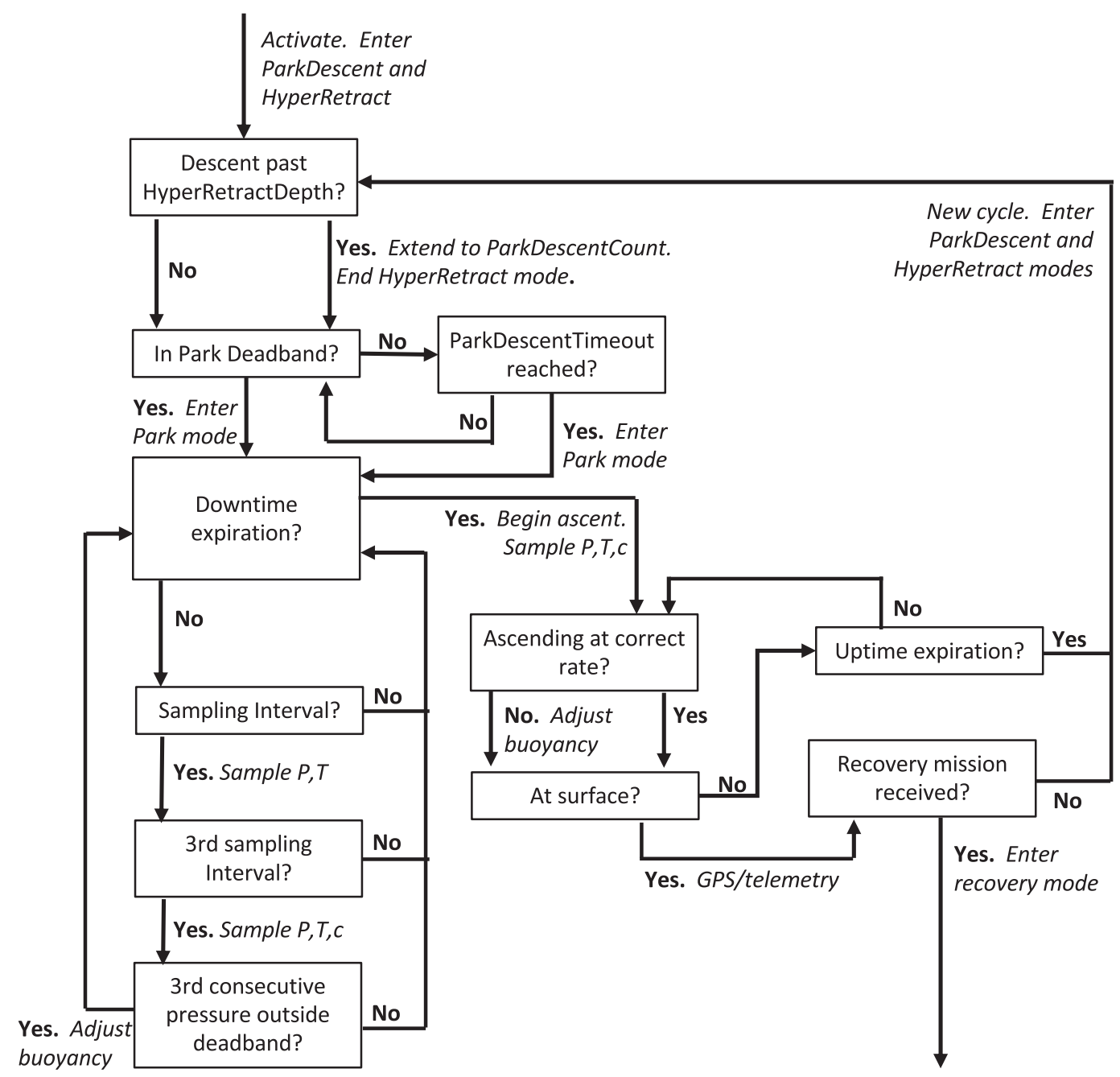

FIG. 6. Flowchart summarizing the steps of an APEX mission as configured for APEX-NBST operation. Normal APEX-NBST operation would not include repeated mission cycles, but this behavior is illustrated for completeness. Sampled parameters are pressure $P$, temperature $T$, and beam attenuation $c$.

If the Recovery Mode activation is not transmitted in time, or if the end of the UpTime period is reached without the float resurfacing, then it will begin a new cycle with the same mission.

The only modification that was made to the standard APEX firmware for this sediment trap application was the inclusion of the HyperRetract feature. Achieving "NBST like" behavior with the available, adjustable parameters is challenging but has been successful. Below, we describe several caveats and lessons learned.

First, an APEX float carrying sediment trap hardware can be expected to entrap a much larger volume of air outside the pressure hull, upon initial deployment. The plastic trap parts have larger coefficients of thermal contraction than the rest of the hull, and often there is no way aboard a ship to maintain the $\sim 40 \mathrm{~L}$ of seawater inside the trap tubes at in situ surface temperature prior to launch. Therefore, even with the HyperRetract functionality enabled, there is a strong possibility an APEX-NBST will not immediately sink upon deployment. Not only is this not ideal from a sample collection standpoint, it is particularly problematic if the "ParkDescentTimeout" value is too short, and the float increases its buoyancy to "ParkDescentCount" while still at the surface. In such cases the trap may remain stuck at the surface for the entire mission cycle. To circumvent this issue, we attach 50-g drop weights via a dissolving link that is timed to release approximately 20 min after deployment. Inexpensive, reproducible results have been achieved with partially predissolved, fruit-flavored Life Savers candies.

A second concern is that, unlike the earlier SOLObased NBSTs with their customized controllers, the autoballasting algorithm of an APEX float does not 
allow for variable buoyancy adjustments that account for how far the float is from its target pressure window, or its vertical velocity through the water (Fig. 6). Instead, the APEX firmware only allows buoyancy adjustments of a fixed magnitude, at fixed time intervals. This unfortunately prevents the APEX-NBST from automatically and quickly compensating for ballasting errors or for differences between expected and actual in situ density and temperature. Instead, the buoyancy setting that corresponds to the target pressure must be known fairly accurately in advance of deployment. To achieve optimal results, each APEX-NBST therefore requires a test deployment in the study area prior to the first sample collection deployment. However, once the correct buoyancy setting is determined, APEX-NBSTs reach their target depths more quickly than do the SOLO-NBSTs (see section 3b).

Despite these caveats, the commercial availability and related likelihood of future support for the APEX platform are attractive. The controller can power and log a larger number of external sensors, introducing the possibility of easy integration of other supporting optical and acoustic particle sensors and imagers. Although the APEX firmware is not optimized for this application, its behavior is predictable. Most commercial profiling floats that are utilized in the long-running, international Argo program have firmware with similar behavior and adjustable parameters, meaning that the APEX-NBST approach could conceivably be extended to many of these platforms.

\section{Technical results from recent field programs}

\section{a. "Are all traps created equal?" Campaign}

In April 2017 a field intercomparison of the most recent SOLO-NBST iteration with PELAGRA traps of NOC design was carried out at the Porcupine Abyssal Plain Sustained Observatory (PAP-SO; $49^{\circ} \mathrm{N}, 16.5^{\circ} \mathrm{W}$ ) aboard the RRS Discovery. By working at the PAP-SO site, the comparisons were made in a setting with minimal horizontal advection, where hydrodynamic biases were predicted to be small. Scientific results, including detailed intercomparisons of laboratory methods, as well as of sediment traps to radiochemical tracer methods, are presented in a separate publication (Baker et al. 2019, manuscript submitted to Prog. Oceanogr.). The main finding in terms of sediment trap performance was that in the deployment setting, conical trap collectors, even aboard neutrally buoyant platforms, undercollected sinking particles relative to cylindrical trap collectors, while particle elemental composition appeared to be broadly consistent across platforms.

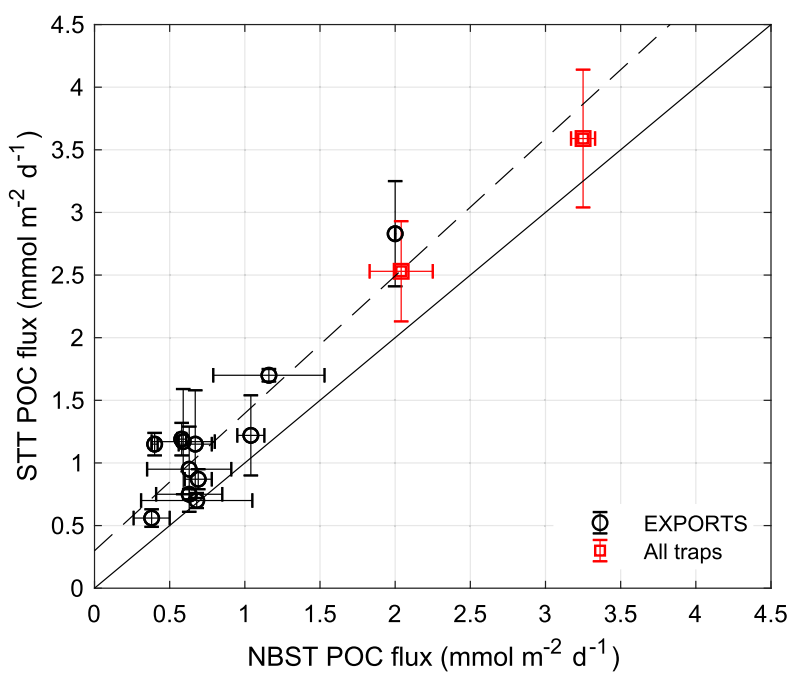

FIG. 7. Particulate organic carbon fluxes measured by STT and identically configured tubes on NBSTs, processed using identical laboratory techniques, and corrected for the influence of "swimmers" (zooplankton that actively swam into the traps). Each symbol is the average of two or three tubes or, in instances in which replicate NBSTs were deployed at the same depth, the average of four tubes from that depth. Error bars are the standard deviation $(N \geq 3)$ or range $(N=2)$ of replicates. Black open circles are observations from the EXPORTS North Pacific deployments, and red open squares are from the "all traps" deployments. The solid black line shows a 1:1 relationship. The dashed black line shows the type-II linear regression with equation $y=1.10( \pm 0.08) \times x+0.3( \pm 0.1)$ and $R^{2}=0.92$.

Cylindrical trap tubes carried aboard surface-tethered, drifting arrays seemed to overcollect slightly relative to identically configured and processed collectors on neutrally buoyant platforms (Fig. 7), but the difference was less pronounced compared to the difference with conical traps.

The relative current velocity past the surface-tethered traps was measured by adding a current meter (Nortek Aquadopp) just below the trap array. In the first of two deployments, horizontal speeds past the STT had a mean and standard deviation of $6 \pm 2 \mathrm{~cm} \mathrm{~s}^{-1}$, whereas, in the second, the mean and standard deviation of the speeds were $12 \pm 4 \mathrm{~cm} \mathrm{~s}^{-1}$. Canonically, speeds less than $10 \mathrm{~cm} \mathrm{~s}^{-1}$ are believed not to impact trap collection efficiency based on laboratory flume experiments (Gardner 2000; see discussion in Buesseler et al. 2007b), but flow conditions are notoriously difficult to monitor and control in the field, and effects are entangled with other sources of uncertainty (i.e., swimmers, sample handling, size and density of sinking particles). It is worth noting that even under the lowerflow conditions of the first deployment, a fast-settling particle with a vertical speed of $500 \mathrm{~m} \mathrm{day}^{-1}\left(0.58 \mathrm{~cm} \mathrm{~s}^{-1}\right)$ would have had an approach angle to the trap mouth of 
TABLE 3. Summary of EXPORTS sediment trap deployments.

\begin{tabular}{|c|c|c|c|c|c|c|c|c|}
\hline $\begin{array}{l}\text { NBST model } \\
\text { and serial no. }\end{array}$ & Epoch & Depth (m) & $\begin{array}{l}\text { Date/time } \\
\text { in (UTC) }\end{array}$ & $\begin{array}{l}\text { Date/time } \\
\text { out (UTC) }\end{array}$ & $\begin{array}{c}\text { Lat } \\
\text { in }\left({ }^{\circ} \mathrm{N}\right)\end{array}$ & $\begin{array}{l}\text { Lon } \\
\text { in }\left({ }^{\circ} \mathrm{E}\right)\end{array}$ & $\begin{array}{c}\text { Lat } \\
\text { out }\left({ }^{\circ} \mathrm{N}\right)\end{array}$ & $\begin{array}{c}\text { Lon } \\
\text { out }\left({ }^{\circ} \mathrm{E}\right)\end{array}$ \\
\hline SOLO-NBST-20 & 1 & 9 & 18 & 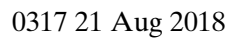 & & 18 & & \\
\hline SOLO-NBST-200 & 2 & 91 & 18 & 2721 Aug & & & & \\
\hline APEX-NBST-303 & 1 & 159 & 1115 Aug 2018 & 92621 Aug 2018 & 50.1146 & -145.0722 & 50.2283 & -145.0248 \\
\hline APEX-NBST-302 & 1 & & 0015 Aug 2018 & 91721 Aug 2018 & 50.1155 & & 50.2173 & \\
\hline APEX-NBST-304 & 1 & & 18 & $094821 \mathrm{Aug}$ & 50.1 & 31 & & 0223 \\
\hline APEX-NBST-305 & 1 & 342 & ug 2018 & 092321 Aug & 50.1 & 39 & & 0325 \\
\hline STT & 1 & $; 195 ; 3$ & 175315 Aug 2018 & 84021 Aug 2018 & 50.1223 & -145 & & -145.0172 \\
\hline SOLO-NB & 2 & 101 & 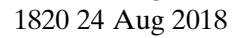 & 022428 Aul & 50 & -14 & & -14 \\
\hline 3ST-200 & 2 & & 18302 & 02252 & & 19 & & 0681 \\
\hline 3ST-303 & 2 & 15 & 18 & 02552 & 50. & & & -14 \\
\hline APEX-NBST-302 & 2 & & 174224 Aug 2018 & 032128 Aug 2018 & 50.4468 & -145.0590 & 50.4 & -145.0132 \\
\hline APEX-NBST-304 & $2^{\mathrm{a}}$ & & 175524 Aug 2018 & 17271 Sep 2018 & 50.4471 & -145.0624 & 50.5530 & -144.8792 \\
\hline APEX-NBST-305 & 2 & 337 & $173024 \mathrm{~A}$ & 0410 & 50. & 74 & 50. & .0080 \\
\hline STT & 3 & 05; 155; 205; & 165524 Aug 2018 & 083829 Aug 2018 & 50.4 & -145 & 50. & -144.8312 \\
\hline SOLO-I & 3 & & 181731 Aug 2018 & 02235 Sep 2018 & 50.6131 & -144.8706 & 50 & -144.8052 \\
\hline SOLO-NBST-200 & 3 & 10 & 18 & & & 22 & & -14 \\
\hline APEX-NBST-303 & 3 & 147 & g 2018 & 0254 & 22 & -14 & 50. & -144.7733 \\
\hline APEX-NBST-302 & $3^{\mathrm{a}}$ & 147 & 03525 Sep 2018 & 17479 Sep 2018 & 50.6043 & -144.7733 & 50.5698 & -144.6900 \\
\hline APEX-NBST-304 & 3 & 198 & & 0253 & & -144.8687 & 50.6 & -144.8013 \\
\hline APEX-NBST-305 & $3^{a}$ & 200 & 03575 & 1817 & & -144 & 50 & -144.7167 \\
\hline SOLO-NBST-20 & 3 & 334 & 174731 Aug 2018 & 03196 Sep 2018 & 50.6083 & -144.8663 & 50.6142 & -144.7640 \\
\hline STT & 3 & $105 ; 155 ; 205 ; 340 ; 510$ & 165831 Aug 2018 & 08176 Sep 2018 & 50.5996 & -144.8657 & 50.4910 & -144.7179 \\
\hline
\end{tabular}

${ }^{a}$ The trap completed more than one mission cycle (see text). In epoch 3 these are shown on separate lines since the floats resurfaced and transmitted positions after both cycles.

about $5.5^{\circ}$ above the horizontal plane. Slower settling particles and faster relative current speeds would only exacerbate this. We observed the STT array to overcollect relative to codeployed NBSTs (which should experience almost zero relative current speeds) in both deployments, and this was more pronounced for most analytes in the second deployment. Bulk particulate organic carbon (POC) flux was enhanced by $25 \%$ and $40 \%$ in the first and second deployments, while bulk particulate inorganic carbon (PIC) flux was enhanced by $102 \%$ and $159 \%$, respectively. Large foraminifera were frequently observed in the traps in this setting and it is possible that these denser, more heavily ballasted particles accounted for the overcollection of PIC by the STT.

\section{b. EXPORTS}

The EXPORTS program (Siegel et al. 2016) aims to collect detailed observations of all processes comprising the biological carbon pump, in order to formulate better-performing, mechanistic models that can be driven by satellite ocean color observations. The first of the EXPORTS field campaigns was conducted at Ocean Station Papa $\left(50^{\circ} \mathrm{N}, 145^{\circ} \mathrm{W}\right)$ in August-September of 2018 and involved multiple, simultaneous deployments of SOLO-NBSTs, APEX-NBSTs, and STT arrays. Because the goal of this paper is to describe the design and performance of the NBST on a technical level, the scientific results of these deployments will be presented in future publications. However, the data from this deployment compose one of the few comprehensive intercomparisons of neutral and surface-tethered trap designs (along with the VERTIGO study; Lamborg et al. 2008; Owens et al. 2013), and so we summarize relevant aspects of that deployment, here.

The EXPORTS North Pacific study site was characterized by weak mean flows, with stronger inertial and tidal motions. Traps were deployed repeatedly over a period of approximately one month, at locations following the mean circulation. Deployments (summarized in Table 3 and Figs. 8 and 9) were carried out three times, with each cycle referred to as an "epoch." Two SOLO-NBSTs were always deployed together at $95 \mathrm{~m}$ while four APEX-NBSTs were deployed at 145,195 , and $330 \mathrm{~m}$. The spatial separation of the STT array from the NBST resurfacing positions (Fig. 8) was presumed to have been driven by wind or wave effects acting on the drifting buoy. The STT array carried a current meter (Aanderaa AADI Seaguard) at $510 \mathrm{~m}$, just below the deepest set of sediment traps. This provided observations of the relative current speeds past the traps at that depth. Respectively, the first, second and third epochs had low and relatively consistent 


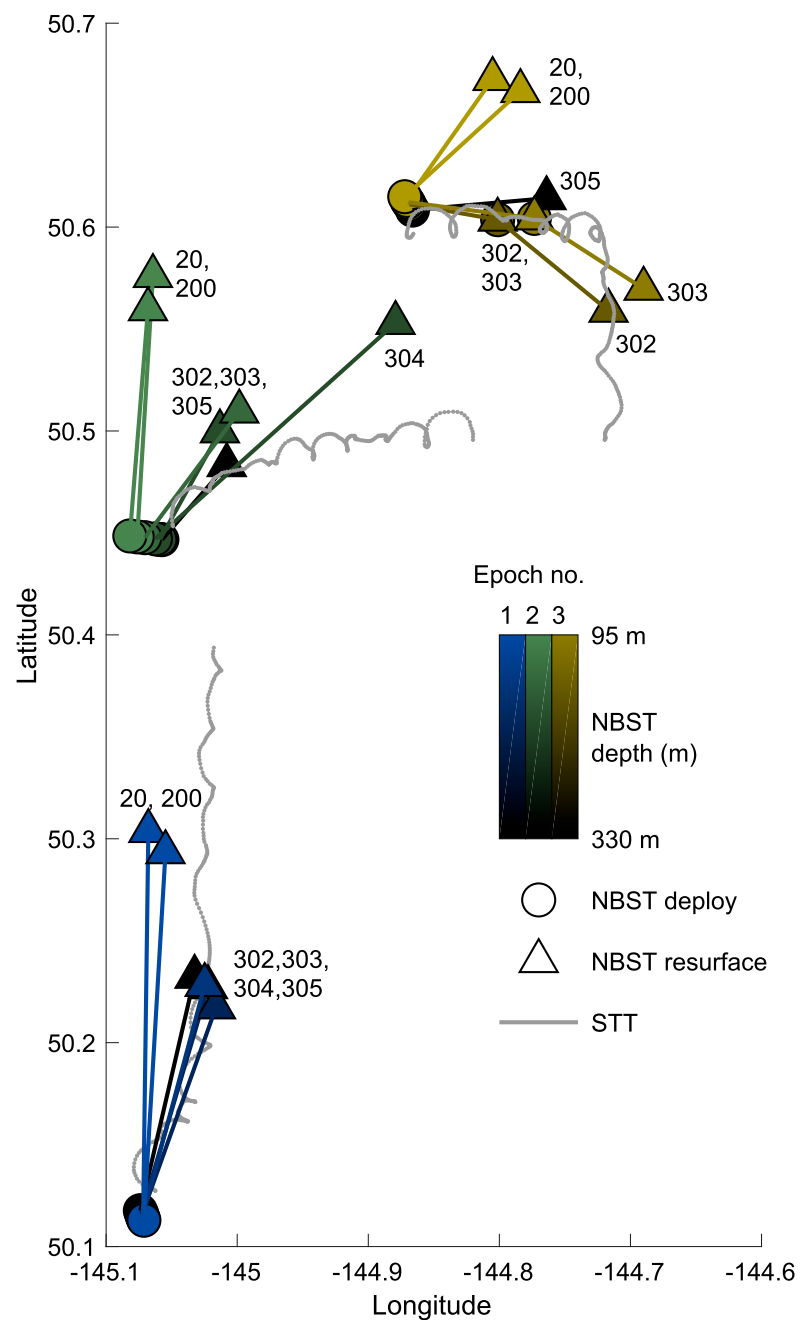

FIG. 8. Deployment and resurfacing positions (circles and triangles, respectively) of sediment traps deployed during the EXPORTS field campaign. The colors represent sampling cycle ("epoch") and trap drift depth. The small labels refer to trap serial number and correspond to Table 3 . The track of the STT buoy is shown in gray and extends over the same time period as the NBST deployments.

horizontal current speeds at the STT array of $6 \pm 3,4 \pm 2$, and $6 \pm 3 \mathrm{~cm} \mathrm{~s}^{-1}$.

As in the "All traps" study (section 3a), we observed the surface-tethered traps to overcollect POC slightly relative to codeployed NBSTs (Fig. 7). A type-II linear regression of POC fluxes to STTs against fluxes to NBSTs in both studies, gives a slope of $1.10 \pm 0.08$ and an intercept of $0.3 \pm 0.1$. This slight overcollection by surface-tethered relative to neutral traps, and the nonzero intercept noted above, are consistent with the observations of Buesseler et al. (2000), Owens et al. (2013), and Baker et al. (2019, manuscript submitted to Prog. Oceanogr.). In a 3-yr time series study,
Owens et al. (2013) found that NBSTs occasionally measured near-zero fluxes while STTs did not, and hypothesized that this might be due to the larger volumes of water that flush through tethered traps. However, there was no apparent dependence of the degree of overcollection by STTs on the relative current speed, consistent with prior intercomparisons (Lamborg et al. 2008).

For the most part, the NBSTs rapidly achieved and then maintained their sampling depths, and resurfaced as expected (Fig. 9). However, some exceptions and observations are highlighted in Fig. 9 and discussed here. Several of the NBSTs were briefly tipped sideways during deployment in the wash behind the ship at the start of epoch 2. Subsequently, one APEX-NBST failed to resurface as expected on 28 August 2018, but instead resurfaced four days later on 1 September 2018 (Fig. 9). After recovery, an analysis of the buoyancy adjustments made by the float indicated that it was approximately $50 \mathrm{~g}$ heavier than expected during the period from 24 until 30 August, suggesting that the 50-g drop weight, attached with an excess of wire, had become entangled during deployment and failed to release as expected during the initial descent. While rough deployments should always be avoided if possible, the episode reinforced the need to carefully redesign the drop-weight attachment system to minimize the possibility of entanglement. Communications problems arising from a reset of the Iridium short-burst data transmission queue finally led to two traps repeating their missions at the end of epoch 3 (Fig. 9).

Overall, the performance of the newer APEX-NBSTs was similar to that of the earlier SOLO-NBST design. As with any new oceanographic field equipment, there are many potential operational improvements, including float firmware modification to allow more flexible and rapid buoyancy adjustments, local data offload, and a built-in burn-wire release. However, in scientific terms the new NBST design is comparable to the older SOLO-NBST, and it has the advantage of being adaptable by other research groups.

\section{Conclusions}

Autoballasting, neutrally buoyant sediment traps are an important tool in studies of the biological carbon pump. Sediment traps in general remain the only way to return samples of sinking material for the increasingly detailed chemical, biological, and optical analyses that are now being employed to tease apart the processes that constitute the biological pump. Only neutrally buoyant traps are largely free from hydrodynamic biases that can arise when traps 


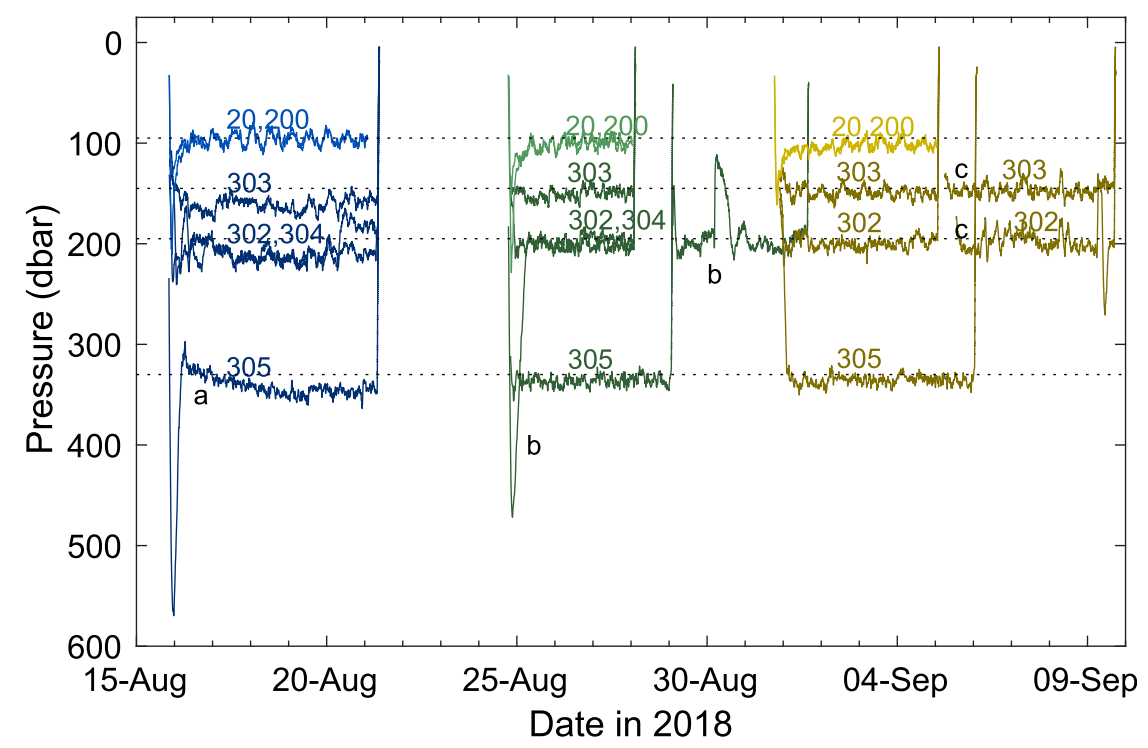

FIG. 9. Pressure-vs-time plots for all NBST deployments during the 2018 EXPORTS program. Horizontal dotted lines indicate target drift depths. Colors correspond to epochs and are the same as in Fig. 8, and shading indicates NBST model, with lighter colors showing SOLO-NBSTs. The small labels refer to trap serial number and correspond to Table 3. During the first two deployment cycles, there were two NBSTs at $95 \mathrm{~m}$ and two at $195 \mathrm{~m}$, and during the third cycle there were two NBSTs at 95 m. Labels "a" and "b" denote events in which the float's compensation for changes in entrapped air or entangled drop weights (event "b" and as described in the main text) resulted in rapid changes in depth. Label "c" denotes instances in which floats did not receive recovery missions upon initial resurfacing and descended for a second mission cycle.

are tethered in a water column with significant velocity shear. The effects on flux collection of fluid flow around tethered traps are rarely simple or linearly dependent on relative flow speed (Buesseler et al. 2007b; Lamborg et al. 2008; Owens et al. 2013; Baker et al. 2019, manuscript submitted to Prog. Oceanogr.) but numerous studies illustrate potential effects that can be magnified by nonzero flow at the trap mouth, and neutral traps offer a conceptually straightforward way of removing this driver (Buesseler et al. 2007b, and references therein). We have presented a detailed description of two decades of improvements to the WHOI-designed NBST, as well as its migration to a commercially available profiling float platform, in the hopes that the technology (or new, related variants) will become more broadly accessible to the scientific community. Two recent studies comparing neutral and surface-tethered platforms carrying identical trap tubes and utilizing identical sample processing methodologies are summarized here, and show that surface-tethered traps seem to overcollect slightly under low-to-moderate relative flow regimes. Additional deployments under high velocity shear conditions will be needed to illustrate relative effects of stronger currents at the mouths of surface-tethered traps. Also, additional improvements to the APEX-NBST are still desirable, primarily the addition of more flexibility to the autoballasting routine so that ballasting errors can be compensated automatically during float operation. Expansion of NBST capabilities might include addition of an expanded optical sensor suite for characterizing suspended particle properties.

Acknowledgments. We are grateful to Teledyne Webb Research for assistance configuring APEX floats, to the WHOI Float Group for ballasting facility and $10 \mathrm{~m}$ tank access, and to numerous colleagues over the years who have helped with NBST deployments and discussions of sampling improvements-in particular, Steve Pike, Rod Johnson, Carl Lamborg, Stephanie Owens, Richard Lampitt, Kev Saw, and Pat Kelly. Special thanks are given to the captains and crews of the R/Vs Atlantic Explorer, Endeavor, Falkor, Revelle, Ride, and Weatherbird II and the RRS Discovery. Funding supporting this work has come from multiple sources over the years: the NSF Chemical Oceanography and Carbon and Water programs (most recently OCE-1660012 and OCE-1659995), the NASA Ocean Biology and Biogeochemistry and New Investigator programs (80NSSC17K0662 and NNX14AM01G), and the Woods Hole Oceanographic Institution Technology Award. 
Data availability statement: All data discussed in this paper are available in public repositories. Data from the "Are all traps created equal?" project (Estapa et al. 2019b) are archived at the NSF Biological and Chemical Oceanography Data Management Office repository. Data from the EXPORTS program (Estapa et al. 2019c) are archived at the NASA SeaBASS repository.

\section{REFERENCES}

Bishop, J. K. B., and T. J. Wood, 2009: Year-round observations of carbon biomass and flux variability in the Southern Ocean. Global Biogeochem. Cycles, 23, GB2019, https://doi.org/10.1029/ 2008GB003206.

,,-- R. A. Davis, and J. T. Sherman, 2004: Robotic observations of enhanced carbon biomass and export at $55^{\circ} \mathrm{S}$ during SOFeX. Science, 304, 417-420, https://doi.org/10.1126/ science.1087717.

Bourne, H. L., J. K. B. Bishop, T. J. Wood, T. J. Loew, and Y. Liu, 2019: Carbon Flux Explorer optical assessment of C, N and P fluxes. Biogeosciences, 16, 1249-1264, https://doi.org/10.5194/ bg-16-1249-2019.

Buesseler, K. O., D. K. Steinberg, A. F. Michaels, R. J. Johnson, J. E. Andrews, J. R. Valdes, and J. F. Price, 2000: A comparison of the quantity and composition of material caught in a neutrally buoyant versus surface-tethered sediment trap. Deep-Sea Res. I, 47, 277-294, https://doi.org/10.1016/S09670637(99)00056-4.

— ocean's twilight zone. Science, 316, 567-570, https://doi.org/ 10.1126/science.1137959.

— traps for estimating upper ocean particle fluxes. J. Mar. Res., 65, 345-416, https://doi.org/10.1357/002224007781567621.

Coale, K. H., 1990: Labyrinth of doom: A device to minimize the "swimmer" component in sediment trap collections. Limnol. Oceanogr., 35, 1376-1381, https://doi.org/10.4319/lo.1990.35.6.1376.

Davis, R. E., J. T. Sherman, and J. Dufour, 2001: Profiling ALACEs and other advances in autonomous subsurface floats. J. Atmos. Oceanic Technol., 18, 982-993, https://doi.org/ 10.1175/1520-0426(2001)018<0982:PAAOAI $>2.0$. CO 2 .

Durkin, C. A., M. L. Estapa, and K. O. Buesseler, 2015: Observations of carbon export by small sinking particles in the upper mesopelagic. Mar. Chem., 175, 72-81, https://doi.org/10.1016/ j.marchem.2015.02.011.

Ebersbach, F., and T. Trull, 2008: Sinking particle properties from polyacrylamide gels during the Kerguelen Ocean and Plateau compared Study (KEOPS): Zooplankton control of carbon export in an area of persistent natural iron inputs in the Southern Ocean. Limnol. Oceanogr., 53, 212-224, https:// doi.org/10.4319/lo.2008.53.1.0212.

Estapa, M. L., K. Buesseler, E. Boss, and G. Gerbi, 2013: Autonomous, high-resolution observations of particle flux in the oligotrophic ocean. Biogeosciences, 10, 5517-5531, https:// doi.org/10.5194/bg-10-5517-2013.

— C. Durkin, K. Buesseler, R. Johnson, and M. Feen, 2017: Carbon flux from bio-optical profiling floats: Calibrating transmissometers for use as optical sediment traps. Deep-Sea Res. I, 120, 100-111, https://doi.org/10.1016/j.dsr.2016.12.003.

— M. L. Feen, and E. Breves, 2019a: Direct observations of biological carbon export from profiling floats in the subtropical
North Atlantic. Global Biogeochem. Cycles, 33, 282-300, https:// doi.org/10.1029/2018GB006098.

— K. K. O. Buesseler, and R. Lampitt, 2019b: Carbon, nitrogen, biogenic silica, thorium-234, and mass fluxes from upper ocean sediment traps at the Porcupine Abyssal Plain Sustained Observatory (PAP-SO) site in the northeast Atlantic Ocean during RRS Discovery cruise DY077 in April of 2017, version 3. Biological and Chemical Oceanography Data Management Office, accessed 26 June 2019, https://doi.org/10.1575/1912/ BCO-DMO.765835.3.

,,-- C. Durkin, and M. Omand, 2019c: EXPORTS North Pacific. SeaWiFS Bio-optical Archive and Storage System (SeaBASS). NASA, accessed 26 June 2019, https://seabass.gsfc.nasa.gov/ archive/SKIDMORE/estapa/EXPORTS/EXPORTSNP/archive/.

, C. A. Durkin, M. M. Omand, and K. O. Buesseler, 2020: Diagnosing export pathways in the biological pump: Sediment trap data from the EXPORTS North Pacific field campaign. 2020 Ocean Sciences Meeting, San Diego, CA, Amer. Geophys. Union, OB14E-0417, https://agu.confex.com/agu/ osm20/meetingapp.cgi/Paper/647488.

Flintrop, C. M., A. Rogge, S. Miksch, S. Thiele, A. M. Waite, and M. H. Iversen, 2018: Embedding and slicing of intact in situ collected marine snow. Limnol. Oceanogr. Methods, 16, 339355, https://doi.org/10.1002/lom3.10251.

Gardner, W. D., 2000: Sediment trap sampling in surface waters. The Changing Ocean Carbon Cycle: A Midterm Synthesis of the Joint Global Ocean Flux Study, R. B. Hanson, H. W. Ducklow, and J. G. Field, Eds., Cambridge University Press, 240-281.

Knauer, G. A., J. H. Martin, and K. W. Bruland, 1979: Fluxes of particulate carbon, nitrogen, and phosphorus in the upper water column of the northeast Pacific. Deep-Sea Res., 26A, 97 108, https://doi.org/10.1016/0198-0149(79)90089-X.

Lamborg, C. H., and Coauthors, 2008: The flux of bio-and lithogenic material associated with sinking particles in the mesopelagic "twilight zone" of the northwest and north central Pacific Ocean. Deep-Sea Res. II, 55, 1540-1563, https://doi.org/10.1016/ j.dsr2.2008.04.011.

Lampitt, R. S., and Coauthors, 2008: Particle export from the euphotic zone: Estimates using a novel drifting sediment trap, ${ }^{234} \mathrm{Th}$ and new production. Deep-Sea Res. I, 55, 1484-1502, https://doi.org/10.1016/j.dsr.2008.07.002.

Lee, C., and Coauthors, 2009: Particulate organic matter and ballast fluxes measured using time-series and settling velocity sediment traps in the northwestern Mediterranean Sea. Deep-Sea Res. II, 56, 1420-1436, https://doi.org/10.1016/ j.dsr2.2008.11.029.

McDonnell, A. M. P., and K. O. Buesseler, 2010: Variability in the average sinking velocity of marine particles. Limnol. Oceanogr., 55, 2085-2096, https://doi.org/10.4319/1o.2010.55.5.2085.

- and - 2012: A new method for the estimation of sinking particle fluxes from measurements of the particle size distribution, average sinking velocity, and carbon content. Limnol. Oceanogr. Methods, 10, 329-346, https://doi.org/10.4319/ lom.2012.10.329.

—_, and Coauthors, 2015: The oceanographic toolbox for the collection of sinking and suspended marine particles. Prog. Oceanogr., 133, 17-31, https://doi.org/10.1016/j.pocean. 2015.01.007.

Middaugh, R. A., and C. A. Goudey, 1993: The dimensional change of polymers under high hydrostatic pressure. Oceans, 93, I149I154, https://doi.org/10.1109/OCEANS.1993.326014.

Owens, S. A., K. O. Buesseler, C. H. Lamborg, J. Valdes, M. W. Lomas, R. J. Johnson, D. K. Steinberg, and D. A. Siegel, 2013: A new time 
series of particle export from neutrally buoyant sediments traps at the Bermuda Atlantic Time-Series Study site. DeepSea Res. I, 72, 34-47, https://doi.org/10.1016/j.dsr.2012.10.011.

Sanders, R. J., and Coauthors, 2016: Controls over Ocean Mesopelagic Interior Carbon Storage (COMICS): Fieldwork, synthesis, and modeling efforts. Front. Mar. Sci., 3, 136, https:// doi.org/10.3389/fmars.2016.00136.

Sherman, A. D., B. W. Hobson, P. R. McGill, R. E. Davis, M. C. McClune, and K. L. Smith, 2011: Lagrangian sediment traps for sampling at discrete depths beneath free-drifting icebergs. Deep-Sea Res. II, 58, 1327-1335, https://doi.org/10.1016/ j.dsr2.2010.11.008.

Siegel, D. A., and W. G. Deuser, 1997: Trajectories of sinking particles in the Sargasso Sea: Modeling of statistical funnels above deep-ocean sediment traps. Deep-Sea Res. I, 44, 15191541, https://doi.org/10.1016/S0967-0637(97)00028-9.

and Coauthors, 2016: Prediction of the export and fate of global ocean net primary production: The EXPORTS science plan. Front. Mar. Sci., 3, 22, https://doi.org/10.3389/fmars.2016.00022.

Stanley, R. H. R., K. O. Buesseler, S. J. Manganini, D. K. Steinberg, and J. R. Valdes, 2004: A comparison of major and minor elemental fluxes collected in neutrally buoyant and surfacetethered sediment traps. Deep-Sea Res. I, 51, 1387-1395, https://doi.org/10.1016/j.dsr.2004.05.010.

Valdes, J. R., and J. F. Price, 2000: A neutrally buoyant, upper ocean sediment trap. J. Atmos. Oceanic Technol., 17, 62-68, https://doi.org/10.1175/1520-0426(2000)017<0062:ANBUOS> 2.0.CO;2. 